\title{
Detection of a plasmaspheric wind in the Earth's magnetosphere by the Cluster spacecraft
}

\author{
I. Dandouras \\ University of Toulouse, UPS-OMP, UMR5277, IRAP (Institut de Recherche en Astrophysique et Planétologie), Toulouse, \\ France
}

CNRS, IRAP, 9 Av. Colonel Roche, BP 44346, 31028 Toulouse cedex 4, France

Correspondence to: I. Dandouras (iannis.dandouras@irap.omp.eu)

Received: 2 April 2013 - Revised: 26 May 2013 - Accepted: 27 May 2013 - Published: 2 July 2013

\begin{abstract}
Plumes, forming at the plasmapause and released outwards, constitute a well-established mode for plasmaspheric material release to the Earth's magnetosphere. They are associated to active periods and the related electric field change. In 1992, Lemaire and Shunk proposed the existence of an additional mode for plasmaspheric material release to the Earth's magnetosphere: a plasmaspheric wind, steadily transporting cold plasmaspheric plasma outwards across the geomagnetic field lines, even during prolonged periods of quiet geomagnetic conditions. This has been proposed on a theoretical basis. Direct detection of this wind has, however, eluded observation in the past. Analysis of ion measurements, acquired in the outer plasmasphere by the CIS experiment onboard the four Cluster spacecraft, provide now an experimental confirmation of the plasmaspheric wind. This wind has been systematically detected in the outer plasmasphere during quiet and moderately active conditions, and calculations show that it could provide a substantial contribution to the magnetospheric plasma populations outside the Earth's plasmasphere. Similar winds should also exist on other planets, or astrophysical objects, quickly rotating and having an atmosphere and a magnetic field.
\end{abstract}

Keywords. Magnetospheric physics (Plasmasphere)

\section{Introduction}

The plasmasphere is the torus of cold and dense plasma which encircles the Earth at geomagnetic latitudes less than about $65^{\circ}$, occupying the inner magnetosphere out to a boundary known as the plasmapause (e.g. Lemaire and Gringauz, 1998; Kotova, 2007). There, the density can drop by 1 to 2 orders of magnitude. The configuration and dynamics of the plasmasphere are highly sensitive to geomagnetic disturbances. During extended periods of relatively quiet geomagnetic conditions the outer plasmasphere can become diffuse, with a gradual fall-off of plasma density. During increasing magnetospheric activity, however, the plasmasphere is eroded and plasmaspheric ions can be peeled off and escape toward the outer magnetosphere.

Observations and modelling efforts have demonstrated that, for instance, plasma tongues can be wrapped around the plasmasphere, shoulders can be formed or plasma irregularities can be detached from the main body of the plasmasphere and form plumes (Lemaire, 2001; Goldstein et al., 2003; Sandel et al., 2003; Dandouras et al., 2005; Pierrard et al., 2008). The in situ observations of the outer plasmasphere obtained by the Cluster constellation provide some novel views of this region (Dandouras et al., 2005; Darrouzet et al., 2009).

Are plasmaspheric plumes the only mode for plasmaspheric material release to the magnetosphere? As indicated above, plasmaspheric plumes are associated to active periods and to fluctuations of the convective large-scale electric field, governed by solar wind conditions. In 1992, however, an additional way for plasmaspheric material release to the magnetosphere was proposed: the existence of a plasmaspheric wind, steadily transporting cold plasmaspheric plasma outwards across the geomagnetic field lines, even during prolonged periods of quiet geomagnetic conditions (Lemaire and Schunk, 1992). This wind is expected to be a slow radial flow pattern, providing a continual loss of plasma from the plasmasphere, for all local times and for $L>\sim 2$. It is 


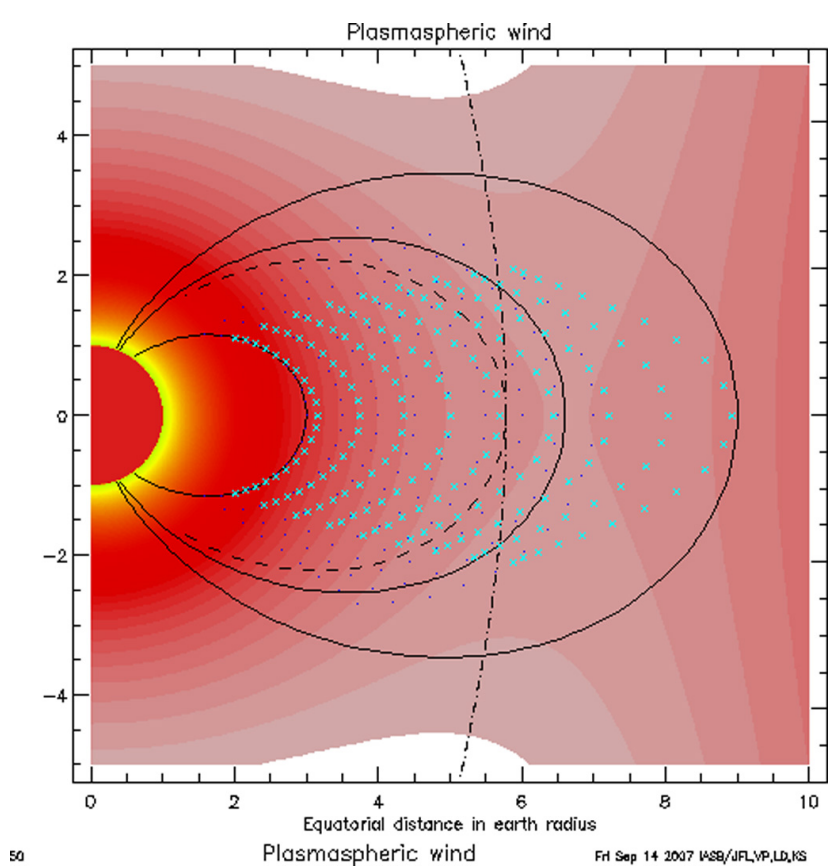

Fig. 1. Plasmaspheric wind formation simulation, as the result from a plasma interchange motion driven by an imbalance between gravitational, centrifugal and pressure gradient forces. It shows the displacements of the plasma elements (the blue x symbols) from their initial positions, i.e. the black dots initially aligned along the dipole magnetic field lines which are represented by the solid lines (Pierrard et al., 2009). Courtesy of Joseph F. Lemaire, Nicolas André and Viviane Pierrard, from a numerical simulation available at http: //plasmasphere.aeronomie.be/plasmaspherewindsimulation.htm.

thus similar to that of the subsonic expansion of the equatorial solar corona (e.g. Meyer-Vernet, 2007).

The existence of this wind has been proposed on a theoretical basis: it is considered as the result of a plasma interchange motion driven by an imbalance between gravitational, centrifugal and pressure gradient forces (André and Lemaire, 2006; Pierrard et al., 2009). Such a radial plasma transport implies that the plasma streamlines are not closed, and therefore the cold plasma elements slowly drift outward from the inner plasmasphere to the plasmapause, along winding up spiral drift paths. Figure 1 shows the displacements of the plasma elements (the blue $\mathrm{x}$ symbols) from their initial positions, i.e. the black dots initially aligned along the dipole magnetic field lines which are represented by the solid lines. The innermost arc of blue $x$ symbols was thus initially along the innermost magnetic field solid line shown in the figure, etc. (see Pierrard et al., 2009). As shown in this figure, this outward radial transport effect is maximum at the geomagnetic equator.

Indirect evidence suggesting the presence of a plasmaspheric wind has been provided in the past from the plasma refilling timing, indicating a continuous plasma leak from the plasmasphere (Lemaire and Shunk, 1992; Yoshikawa et

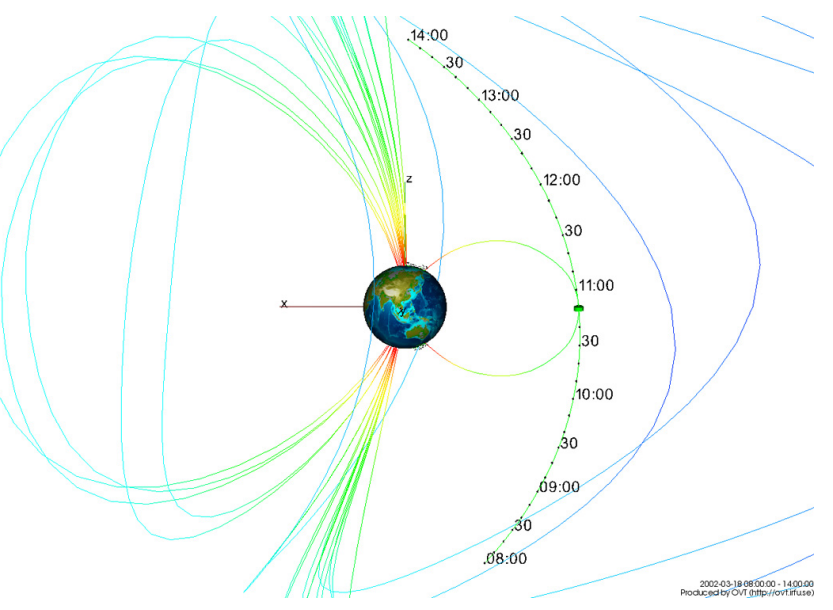

Fig. 2. Cluster C3 (spacecraft 3) orbit, in green, for the 18 March 2002 event, projected on the Tsyganenko (1989) magnetic field model, GSE coordinate system. Orbit Visualization Tool plot, courtesy of the OVT team.

al., 2003), and from the smooth density transitions from the plasmasphere to the subauroral region, observed during quiet conditions and at various magnetic local times (Tu et al., 2007). Direct detection of this wind has, however, eluded observation in the past.

In this study we provide the first experimental direct evidence for the plasmaspheric wind. It is based on the analysis of the ion distribution functions, acquired in the outer plasmasphere by the CIS experiment onboard the Cluster spacecraft.

\section{Instrumentation}

The Cluster mission is based on four identical spacecraft launched in 2000 on similar elliptical polar orbits with a perigee at about $4 R_{\mathrm{E}}$ and an apogee at $19.6 R_{\mathrm{E}}$ (Escoubet et al., 2001). This nominal orbit allows Cluster to cross the ring current region, the radiation belts and the outer plasmasphere, from south to north, during every perigee pass, and to obtain their latitudinal profile, following almost the same flux tube (Dandouras et al., 2005, 2009). Moreover, due to the annual precession of its orbit, Cluster is crossing the equator at all MLT ranges over a year.

The Cluster Ion Spectrometry (CIS) experiment onboard Cluster consists of the two complementary spectrometers, HIA and CODIF, and provides the 3-D ion distributions with one spacecraft spin (4s) time resolution (Rème et al., 2001). Furthermore, the mass-resolving spectrometer CODIF provides the ionic composition of the plasma for the major magnetospheric species $\left(\mathrm{H}^{+}, \mathrm{He}^{+}, \mathrm{He}^{++}\right.$and $\left.\mathrm{O}^{+}\right)$, from a thermal energy of $\sim 25 \mathrm{eV} \mathrm{e}^{-1}$ to about $40 \mathrm{keV} \mathrm{e}^{-1}$. The CODIF instrument combines ion energy per charge selection by deflection in a rotationally symmetric toroidal electrostatic analyser, with a subsequent time-of-flight analysis. 


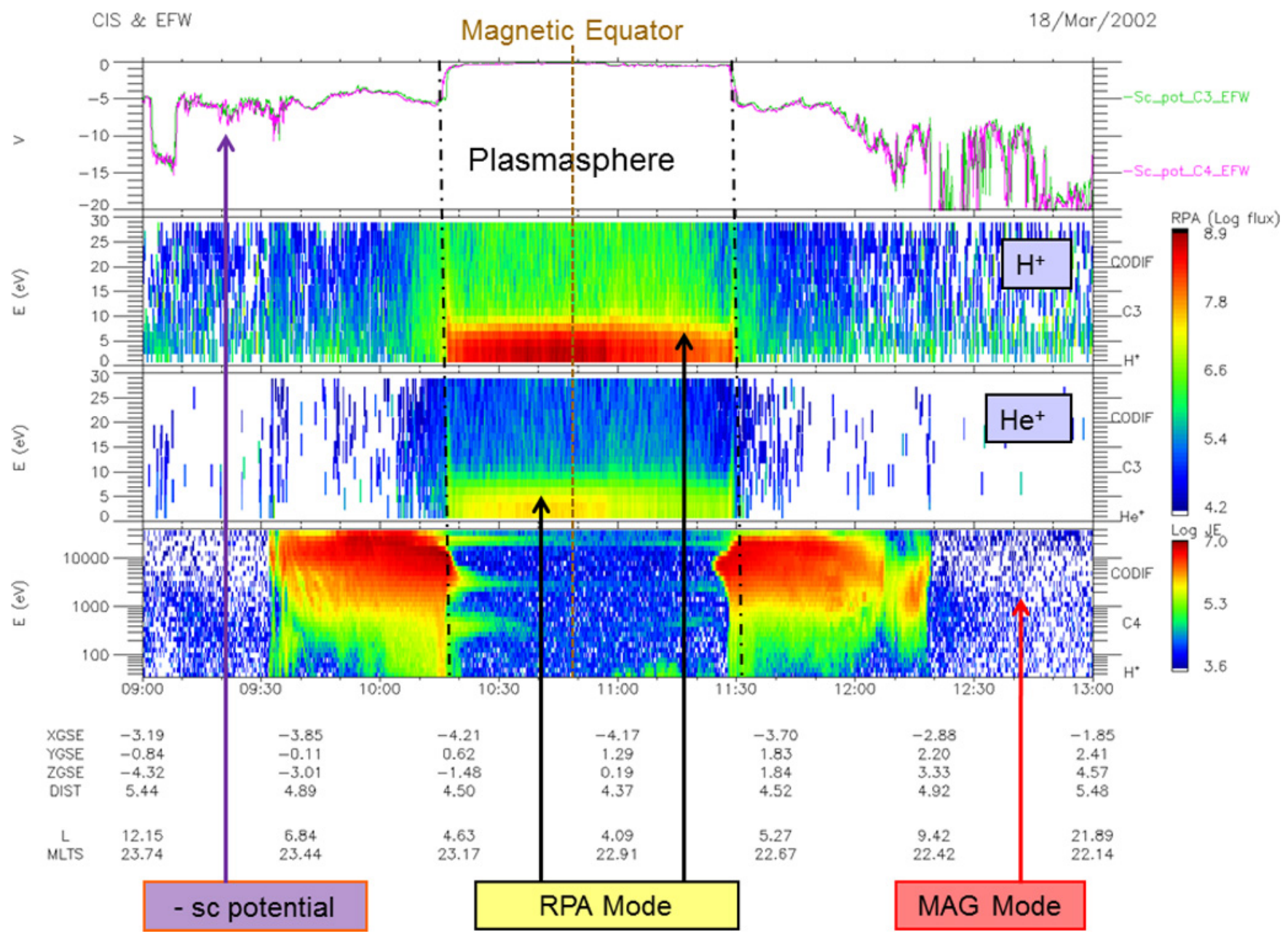

Fig. 3. Cluster C3 (spacecraft 3) and C4 data for the 18 March 2002 event. From top to bottom: negative of the spacecraft potential measured by the EFW experiment ( $\mathrm{C} 3$ in green and $\mathrm{C} 4$ in magenta), which is a proxy of changes in the plasma density; CODIF $\mathrm{C} 3$ omnidirectional $\mathrm{H}^{+}$ and $\mathrm{He}^{+}$energy-time spectrograms in particle flux units $\left(\mathrm{cm}^{-2} \mathrm{~s}^{-1} \mathrm{sr}^{-1} \mathrm{keV}^{-1}\right)$ in the RPA mode (low-energy ion detection); CODIF C4 omnidirectional energy-time spectrogram in particle energy flux units $\left(\mathrm{keV} \mathrm{cm}^{-2} \mathrm{~s}^{-1} \mathrm{sr}^{-1} \mathrm{keV}^{-1}\right)$ for $\mathrm{H}^{+}$in normal magnetospheric mode (energetic ions); spacecraft coordinates in the GSE system, geocentric distance, $L$ parameter and spacecraft magnetic local time for C3.

An MCP (microchannel plate) detector ring is used to detect both the incoming ions and the secondary electrons, provided by the time-of-flight system. The detector ring is segmented into 16 anodes, each anode covering $22.5^{\circ}$. These anodes are grouped into two sections of $180^{\circ}$ each, and only one of the two sections is operated at a time.

In addition CODIF is equipped with a retarding potential analyser (RPA) device in the aperture system, which allows more accurate measurements in the $\sim 0.7-25 \mathrm{eV} \mathrm{e}^{-1}$ energy range (with respect to the spacecraft potential), covering the plasmasphere energy domain. The operation on CODIF of the RPA mode $\left(\sim 0.7-25 \mathrm{eV} \mathrm{e}^{-1}\right.$ energy range) and of the normal magnetospheric modes $\left(\sim 25 \mathrm{eV} \mathrm{e}^{-1}\right.$ to $\sim 40 \mathrm{keV} \mathrm{e}^{-1}$ energy range) is mutually exclusive. The same MCP detector ring is used in both cases. The RPA mode is operated on 1 out of 10 orbits on average, and not always on all of the spacecraft.
The instrument is mounted on the spacecraft platform, with the field of view tangent to the cylindrical surface of the spacecraft. At any instant ions arriving along any direction in this plane are detected, providing an instantaneous half-2$\mathrm{D}$ distribution (over $180^{\circ}$ ), and the anode segmentation provides the elevation direction of the incoming ions. The third dimension of a 3-D distribution is provided by the rotation of the detector plane with the spacecraft spin, which implies that a full 3-D ion distribution is acquired after a complete spacecraft rotation $(4 \mathrm{~s})$. The azimuthal direction of the incoming ions is then given by the spacecraft spin phase.

In this study, data acquired during the operation of the CODIF RPA mode in the outer plasmasphere are used. 
Spacecraft position on the ecliptic plane when close to magnetic equator (18 March 2002 event)
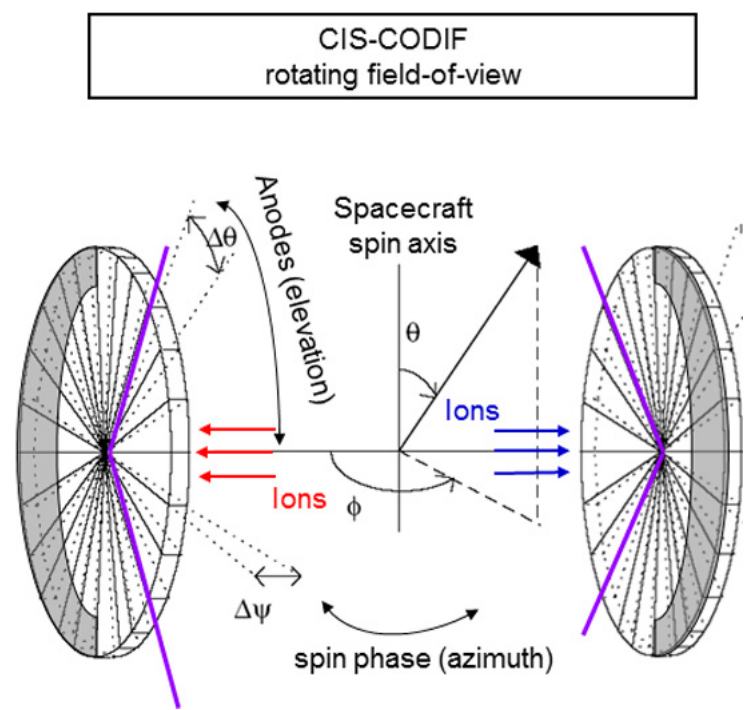

Fig. 4. Principle for the acquisition of two partial distribution functions: one corresponding to ions flowing radially outwards (blue arrows) and one to ions flowing radially inwards (red arrows). The left panel shows schematically the position of the spacecraft on the ecliptic plane, when it was close to the magnetic equator. The right panel shows the CIS-CODIF rotating field of view, first during the portion of the spacecraft spin phase when it was detecting ions flowing radially inwards (red arrows), and then, half a spin period later, when the same anodes were detecting ions flowing radially outwards (blue arrows). The thick magenta lines delimit the instrument field of view in $\pm 45^{\circ}$ in elevation (anodes selected for this study). The grey-shaded part of the detector is not used in this mode.

\section{Observations and analysis}

\subsection{Plasmasphere cut in the night-side sector: 18 March 2002 event}

On 18 March 2002, the Cluster constellation crossed the outer plasmasphere in the pre-midnight sector (23:00 MLT), during quiet magnetospheric conditions $(\mathrm{Kp}=1+)$. The corresponding orbit plot is shown in Fig. 2. Cluster C3 (spacecraft 3), as shown in Fig. 3, was in the RPA mode detecting ions in the $\sim 0.7-25 \mathrm{eVe}^{-1}$ energy range, while $\mathrm{C} 4$ was in a normal magnetospheric mode $\left(\sim 25 \mathrm{eV} \mathrm{e}^{-1}\right.$ to $\sim 40 \mathrm{keV} \mathrm{e}^{-1}$ energy range). $\mathrm{C} 3$ and $\mathrm{C} 4$ during this event were very close to each other, separated by typically $130 \mathrm{~km}$, essentially along the $Z_{\mathrm{GSE}}$ direction. They were inbound from the southern lobe and entered into the near-Earth plasma sheet at 09:32 UT, as revealed by the energetic ion populations detected by $\mathrm{C} 4$ (bottom spectrogram of Fig. 3). The plasmapause was crossed at 10:16:52 UT, at $L=4.7$, when C3 entered into a dense population of low-energy $(<10 \mathrm{eV}) \mathrm{H}^{+}$ and $\mathrm{He}^{+}$ions, shown in the two middle panels of Fig. 3 and characteristic of the plasmasphere (Dandouras et al., 2005). The negative of the spacecraft potential for $\mathrm{C} 3$ and $\mathrm{C} 4$, measured by the EFW experiment (Gustafsson et al., 2001) and shown in the top panel of Fig. 3, is a good proxy of changes in the plasma density (Pedersen et al., 2001, 2008). It confirms the entrance into the plasmasphere, almost simultaneously for $\mathrm{C} 3$ and $\mathrm{C} 4$. At the same time, the intense fluxes of energetic ions, measured by $\mathrm{C} 4$, gave their place to multiple nose-like structures and tenuous ion drift bands (Vallat et al., 2007; Dandouras et al., 2009). It should be also noted that inside the plasmasphere, as shown by the top panel of Fig. 3, the spacecraft potential is $\sim 0$.

The Cluster spacecraft crossed the magnetic equator at 10:49 UT, at $L=4.1$, and then exited the plasmasphere at 11:29:28 UT, at $L=4.7$. Note that during the two crossings of the plasmapause boundary layer, inbound and outbound, a more energetic ion population appeared within this thin layer, up to $20 \mathrm{eV}$ compared to up to $10 \mathrm{eV}$ inside the plasmasphere.

The ion data that will be analysed, in search of signatures of a plasmaspheric wind, are the $\mathrm{H}^{+}$and $\mathrm{He}^{+}$distribution functions acquired by $\mathrm{C} 3$ in the plasmasphere during the magnetic equator crossing. Since this wind is expected to be a radial outward flow pattern, partial distribution functions are constructed by selecting equally sized but oppositely directed solid angles, i.e. one solid angle in the phase space containing all ions flowing radially outwards and one equally sized solid angle containing all ions flowing radially inwards. In the absence of any net outward (or inward) plasma flow the space phase densities in each of these two oppositely directed solid angles should be equal.

Figure 4 shows schematically the principle used in defining these two partial ion distribution functions. They both correspond to the ions detected by the four central detector anodes, covering in elevation $\pm 45^{\circ}$ above/below the spacecraft spin plane, which is approximately the ecliptic plane. The azimuthal range covered by each of these two partial distribution functions is $67.5^{\circ}$, corresponding to three adjacent 

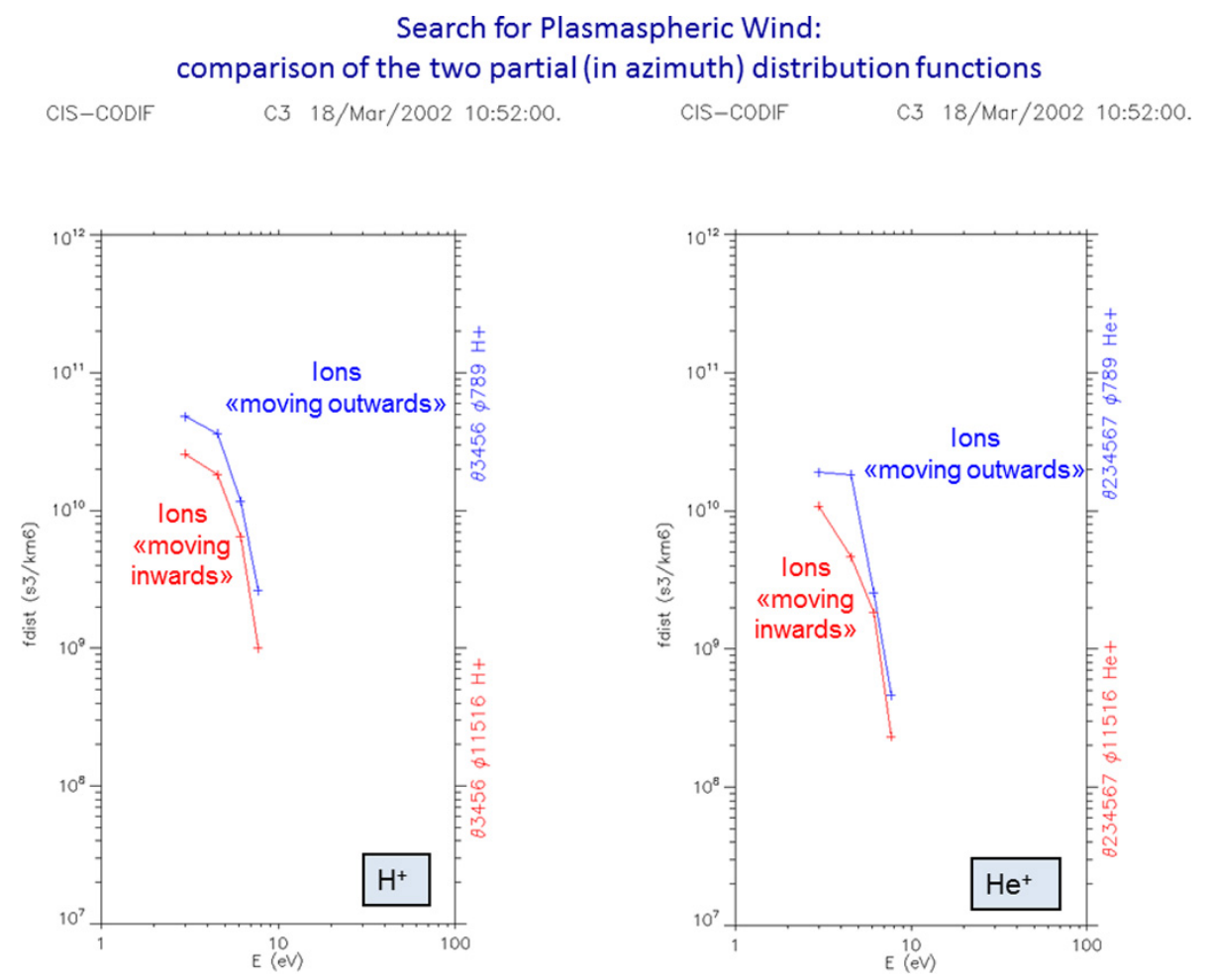

Fig. 5. Partial distribution functions in the outer plasmasphere and close to the magnetic equator, corresponding to ions flowing radially outwards (blue plots) and to ions flowing radially inwards (red plots). Left panel is for $\mathrm{H}^{+}$ions and right panel is for He ${ }^{+}$ions. Ordinate axis is in phase space density units (ions $\mathrm{s}^{3} \mathrm{~km}^{-6}$ ). The systematic imbalance between the outwards and inwards propagating ions reveals a net outward flow.

elementary azimuthal bins of $22.5^{\circ}$ each one, and is centred on the radially outward/inward directions respectively. These two directions are defined with respect to the centre of the Earth. The two oppositely directed partial distribution functions are constructed by acquiring ions arriving only in the corresponding portion of the spacecraft spin phase, and by accumulating data during 16 successive spins (64 s). During each spin both partial distribution functions acquire data, alternating between them every half spin period. In this way sufficient counting statistics are accumulated and any effects due to eventual temporal variations in the plasma are removed, because the two oppositely directed partial distribution functions are acquired over essentially the same $64 \mathrm{~s}$ period, with a time shift of only $2 \mathrm{~s}$ between them.

With this technique the same detector anodes are used to acquire the two oppositely directed partial distribution functions, which are thus obtained with the same transfer functions and particle detection efficiencies. This implies that any eventual drift in the instrument calibration would have no effect on the end result, because it would affect both partial distribution functions in exactly the same way and would not introduce any instrument related asymmetry between them.

The partial distribution functions derived as described in the above paragraphs, close to the magnetic equator, are shown in Fig. 5. Left panel is for $\mathrm{H}^{+}$ions and right panel is for $\mathrm{He}^{+}$ions. Phase space density of ions moving radially outwards is plotted in the blue curves, whereas for ions moving radially inwards it is plotted in the red curves.

These plots reveal a clear imbalance between the outward and inward moving ions, both for $\mathrm{H}^{+}$and for $\mathrm{He}^{+}$ions, corresponding to a net outward flow. Note that this imbalance is systematic for all plasmaspheric ion energies, and for each energy channel there are typically twice as much ions moving radially outwards than there are moving radially inwards. A total of $\sim 1300$ detected $\mathrm{H}^{+}$ions populate these partial distribution functions.

Figure 6 shows again these partial distribution functions, but in a 2-D x-y plot (GSE plane). The net outward flow is again present. The spacecraft velocity has been removed here. Its effect is however negligible in these partial distribution functions because the spacecraft is moving mainly along the z-axis, from south to north. The absence of ions in the centre of this 2-D distribution (white circle) is the effect of the lower energy threshold of the CODIF RPA $(\sim 0.7 \mathrm{eV})$.

\subsection{Plasmasphere cut in the afternoon-side sector: 4 July 2001 event}

Another example of a Cluster crossing of the outer plasmasphere during quiet magnetospheric conditions $(\mathrm{Kp}=1+)$, 


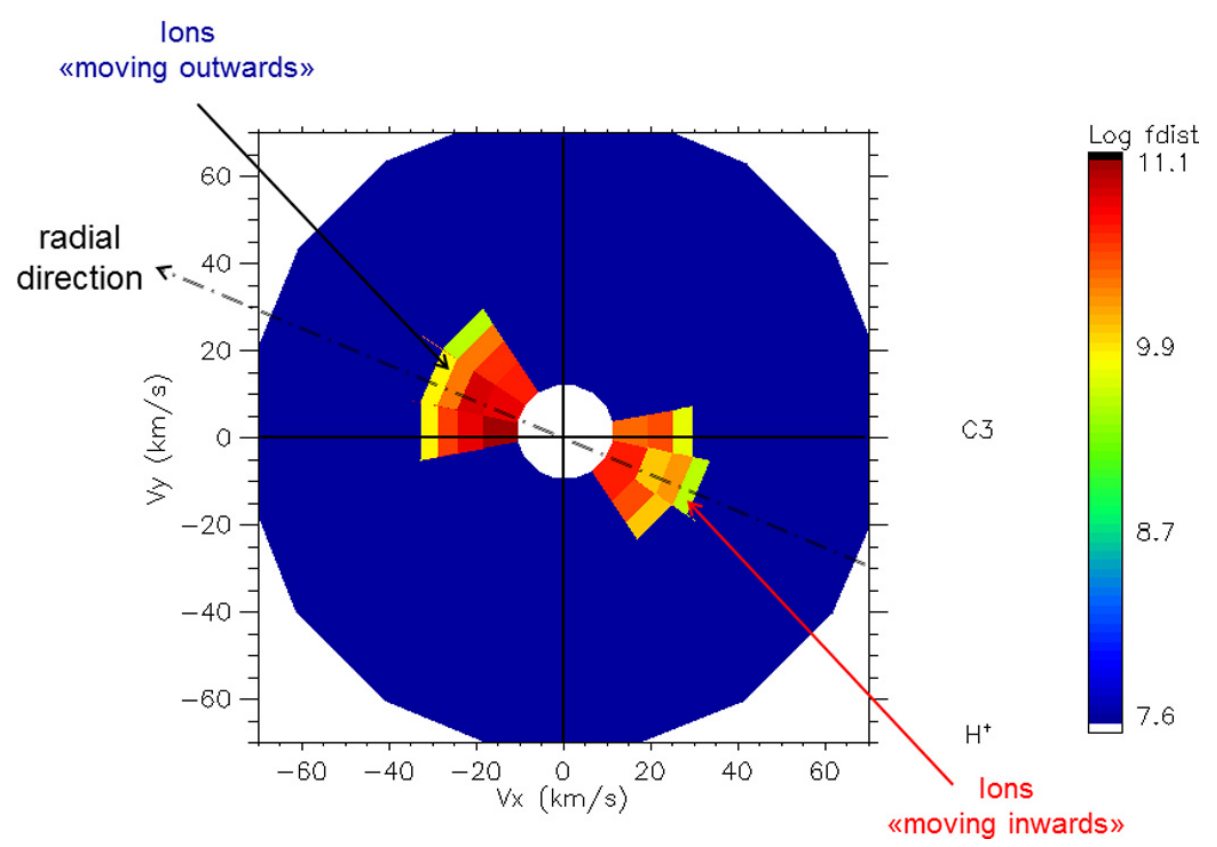

Fig. 6. Partial 2-D distribution function in the outer plasmasphere and close to the magnetic equator, in the $\mathrm{x}-\mathrm{y}$ plane $(\mathrm{GSE})$ : $\mathrm{H}^{+}$ions flowing in the two $67.5^{\circ}$ wide azimuthal sectors that are centred on the radially outward/inward directions respectively. Measurements in azimuthal directions other than these two $67.5^{\circ}$ sectors around the radial direction have been masked for clarity. The white circles at the centre and at the outer edge of the distribution correspond to the RPA lower and upper energy limit respectively. The spacecraft velocity has been removed. Phase space density units (ions $\mathrm{s}^{3} \mathrm{~km}^{-6}$ ).

but this time in the afternoon sector (15:00 MLT), is shown in the 4 July 2001 event of Fig. 7. The plasmapause boundary is less sharp than for the 18 March 2002 event, but there is a clear entry into the plasmasphere at 11:29 UT, at $L=5.4$. The Cluster $\mathrm{C} 3$ spacecraft crossed the magnetic equator from south to north at 12:12 UT, at $L=4.0$, and then exited the plasmasphere at 12:48 UT, at $L=4.8$. Following the exit from the plasmasphere, a plasma plume was observed at 12:58 UT, very close to the plasmapause.

The two oppositely directed partial ion distribution functions, acquired for ions moving radially outwards (plotted in the blue curves) and for ions moving radially inwards (plotted in the red curves), are plotted in Fig. 8. These have been calculated using the same technique as for the 18 March 2002 event, and adapting the selected elementary azimuthal bins to the MLT position of the spacecraft during this event, so as to represent the radially outward/inward directions respectively.

These partial ion distribution functions reveal again the same imbalance between the outward and inward moving ions, both for $\mathrm{H}^{+}$and for $\mathrm{He}^{+}$ions, corresponding to a net outward flow.

\subsection{Distribution of observed events in the equatorial plane}

Six Cluster equatorial crossings of the outer plasmasphere have been investigated in detail (cf. Table 1). All these crossings occurred during quiet or moderately active magnetospheric conditions $(\mathrm{Kp}<3)$, for which the RPA mode was in operation. During all of these the same net outward flow was systematically observed. Figure 9 shows the distribution of these events in the $X_{\mathrm{GSE}}-Y_{\mathrm{GSE}}$ plane. It appears that this outward plasma flow occurs in all MLT sectors, and thus it is not related to the local electric field configuration, which presents a strong local-time dependence due to the superposition of a radial corotation electric field with a mainly dawn to dusk convection electric field (e.g. Volland, 1973; McIlwain, 1986; Pierrard et al., 2008). This convection electric field configuration has been often used to explain the erosion of the plasmasphere and the formation of plumes, with the most salient feature the formation of a large-scale plume in the afternoon sector (Goldstein et al., 2003; Darrouzet et al., 2009). The here-observed outward plasma flow, in the outer plasmasphere, constitutes apparently another mode for plasmaspheric material release into the magnetosphere, which operates continuously and in all local-time sectors. 


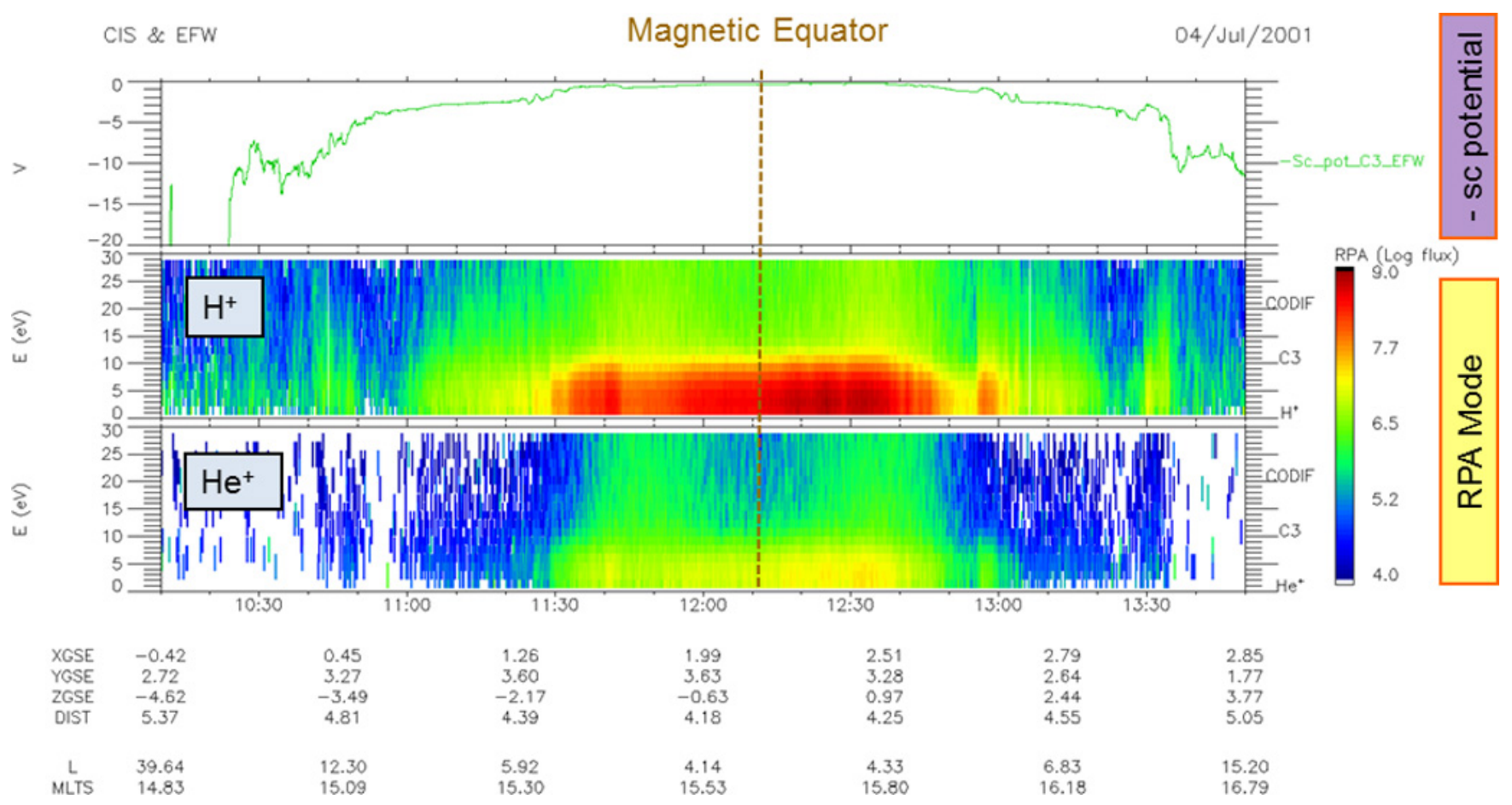

Fig. 7. Cluster C3 data for the 4 July 2001 event. From top to bottom: negative of the spacecraft potential measured by the EFW experiment, which is a proxy of changes in the plasma density; CODIF omnidirectional $\mathrm{H}^{+}$and $\mathrm{He}^{+}$energy-time spectrograms in particle flux units $\left(\mathrm{cm}^{-2} \mathrm{~s}^{-1} \mathrm{sr}^{-1} \mathrm{keV}^{-1}\right)$ in the RPA mode (low-energy ions detection); spacecraft coordinates in the GSE system; $L$ parameter and spacecraft magnetic local time.

The average radial outflow velocity, as deduced from the anisotropy of the ion distribution functions, is $1.4 \mathrm{~km} \mathrm{~s}^{-1}$. Considering the following, we can calculate the resulting plasma loss rate from the plasmasphere to the outer magnetosphere: (a) a total plasma density of the order of $100 \mathrm{~cm}^{-3}$, in the outer plasmasphere and at a geocentric distance of typically $4 R_{\mathrm{E}}$, as deduced from the measurements of the WHISPER sounder experiment onboard Cluster (Décréau et al., 2001; Darrouzet et al., 2009); (b) a continuous radial outflow that at these distances is essentially for the plasma between $30^{\circ}$ north and $30^{\circ}$ south geomagnetic latitude, i.e. over $2 \pi \mathrm{sr}$ (cf. Fig. 1). It results that $\sim 5 \times 10^{26}$ ions s $^{-1}$ are continuously escaping from the plasmasphere, transported by this plasmaspheric wind.

\section{Discussion and conclusions}

The anisotropy of the low-energy ion distribution functions acquired by the CIS experiment onboard Cluster in the outer plasmasphere, close to the equatorial plane, has been used in order to reveal a systematic radial outflow of the plasma. This outflow has been observed during all quiet or moderately active magnetospheric conditions events analysed, in all MLT sectors, and is consistent with the plasmaspheric wind proposed on a theoretical basis by Lemaire and Schunk (1992).
Table 1. Cluster equatorial crossings of the outer plasmasphere analysed, during quiet or moderately active magnetospheric conditions, for which the RPA mode was in operation. The distribution of these events in the $X_{\mathrm{GSE}}-Y_{\mathrm{GSE}}$ plane is shown in Fig. 9.

\begin{tabular}{ccccrrl}
\hline Day & Month & Year & UT & $X_{\text {GSE }}$ & $Y_{\text {GSE }}$ & Kp \\
\hline 4 & 7 & 2001 & $12: 12$ & 2.23 & 3.53 & $1+$ \\
9 & 8 & 2001 & $05: 08$ & 3.89 & 1.68 & 2 \\
27 & 12 & 2001 & $14: 58$ & -1.65 & -3.92 & $2-$ \\
18 & 3 & 2002 & $10: 49$ & -4.22 & 1.14 & $1+$ \\
2 & 6 & 2002 & $13: 22$ & 0.11 & 4.34 & $3-$ \\
4 & 10 & 2006 & $06: 53$ & 3.54 & -1.38 & $1-$ \\
\hline
\end{tabular}

During high-activity periods, however, plasmaspheric outflows are dominated by plumes released from the plasmapause.

Following the erosion of the plasmasphere after a severe geomagnetic storm, the plasma refilling time at $L>3$ can be 4 days or even as long as 8 days (Park, 1970; Kotova, 2007; Obana et al., 2010). Considering a simple refilling scenario, with an ionisation flux varying with time as the equatorial density increases, Lemaire and Schunk (1992) estimated the equatorial densities in drifting and refilling flux tubes and noted that a flux tube located at $R=4 R_{\mathrm{E}}$ would take only 2.5 days to completely refill and reach a state of diffusive 
Search for Plasmaspheric Wind: comparison of the two partial (in azimuth) distribution functions

CIS-CODIF C3 04/Jul/2001 12:15:00. CIS-CODIF C3 04/Jul/2001 12:15:00.
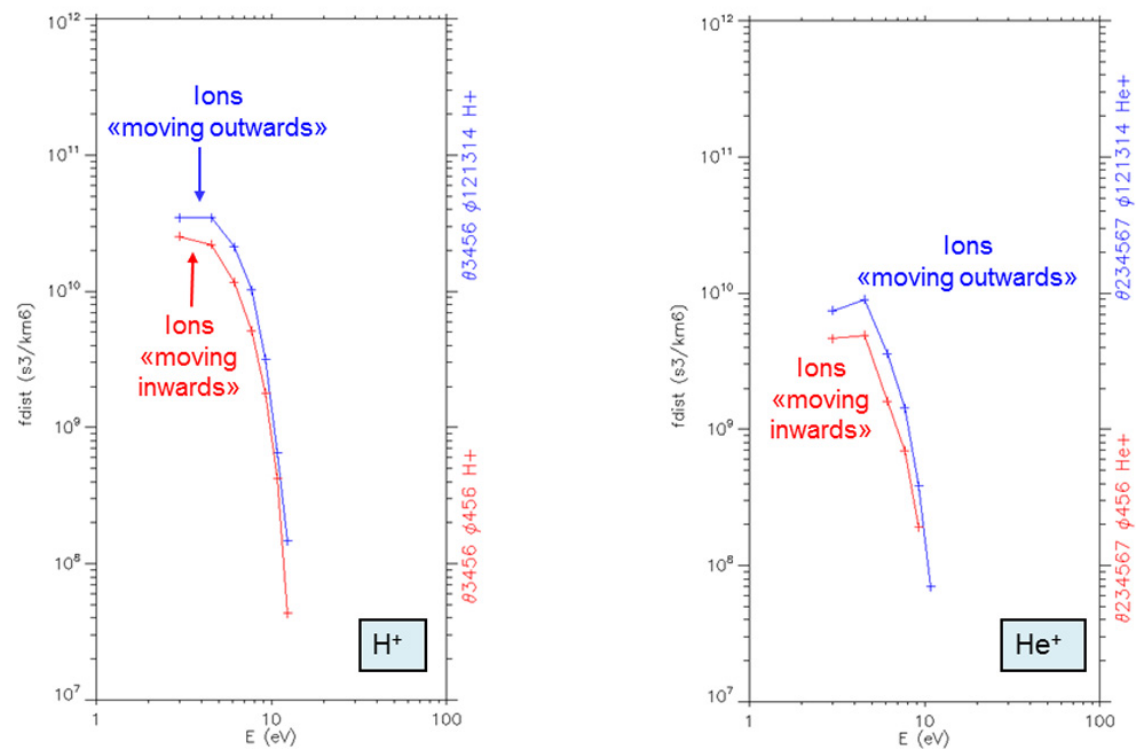

Fig. 8. Partial distribution functions in the outer plasmasphere and close to the magnetic equator, corresponding to ions flowing radially outwards (blue plots) and to ions flowing radially inwards (red plots). Left panel is for $\mathrm{H}^{+}$ions and right panel is for He ${ }^{+}$ions. Ordinate axis is in phase space density units (ions $\mathrm{s}^{3} \mathrm{~km}^{-6}$ ). The systematic imbalance between the outwards and inwards propagating ions reveals a net outward flow.

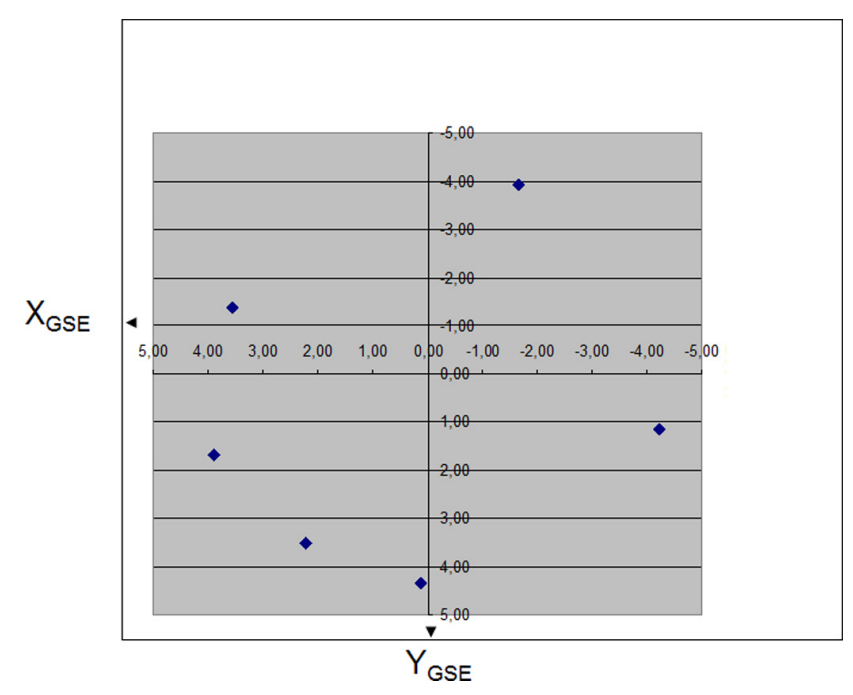

Fig. 9. Distribution in the $X_{\mathrm{GSE}}-Y_{\mathrm{GSE}}$ plane of the events during which a net outward plasma flow was observed by Cluster inside the outer plasmasphere.

equilibrium. This refilling timing difference, between calculated and observed times, suggests a continuous plasma leak from the plasmasphere, even during quiet conditions, consistent with the plasmaspheric wind observations reported here. Evidence for such a continuous plasma leak, outside the plasmapause, has been also provided by global EUV imaging of the plasmasphere (Yoshikawa et al., 2003).

The here-calculated plasma transport rate due to the plasmaspheric wind $\sim 5 \times 10^{26}$ ions s $^{-1}$ constitutes a plasma source for the outer magnetosphere which has to be compared to the other known plasma sources. The solar wind source is of the order of $\sim 10^{27}$ ions s ${ }^{-1}$ and the high-latitude ionospheric source is of the order of $\sim 10^{26}$ ions s $^{-1}$, varying by a factor of $\sim 3$ as a function of the activity level and particularly dependent on the IMF orientation (Moore et al., 2005; Haaland et al., 2009; Li et al., 2012). The plasmaspheric plumes, which are a persistent feature during active periods, contribute during these periods by typically $\sim 2 \times 10^{26}$ ions s $^{-1}$ to the magnetospheric populations (Borovsky and Denton, 2008). It appears thus that the plasmaspheric wind constitutes a substantial plasma source for the magnetosphere, outside the plasmasphere, which is comparable to the other sources and which operates continuously, even during prolonged periods of quiet geomagnetic conditions.

Can these ions be detected in the outer magnetosphere, once they get outside of the dense plasmasphere? Detection of low-energy ions in tenuous plasma environments is complicated by the positive charging of the spacecraft in these 


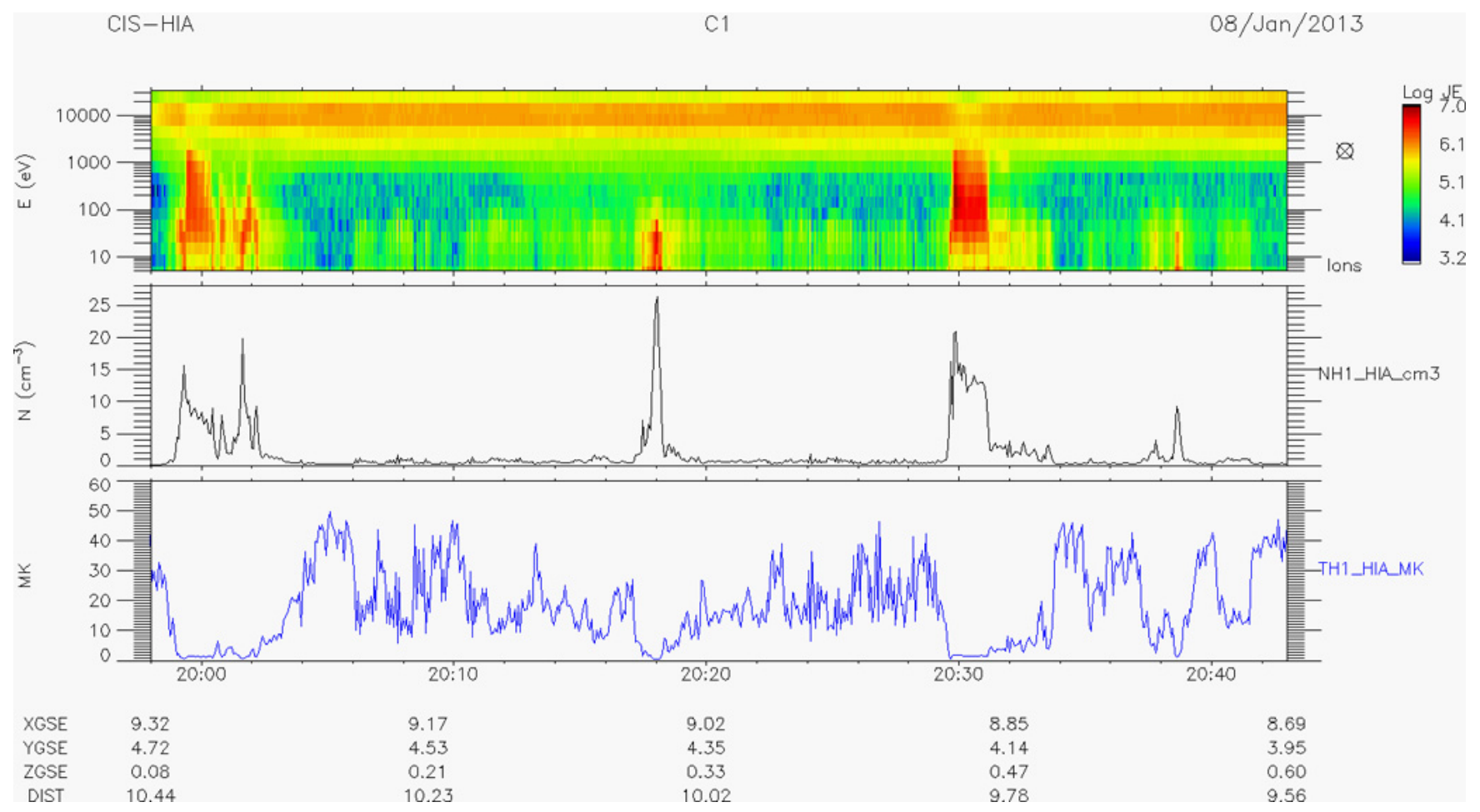

Fig. 10. Cluster $\mathrm{C} 1$ data obtained in the dayside outer magnetosphere on 8 January 2013, after a prolonged period of very quiet magnetospheric conditions. From top to bottom: HIA omnidirectional ion energy-time spectrogram in particle energy flux units $\left(\mathrm{keV} \mathrm{cm}^{-2} \mathrm{~s}^{-1} \mathrm{sr}^{-1} \mathrm{keV}^{-1}\right)$; ion density measured by HIA in particles $\mathrm{cm}^{-3}$; ion temperature in MK; spacecraft coordinates in the GSE system.

regions, up to several tens of volts, due to photoelectron emission from the sunlit spacecraft surfaces (Pedersen et al., 2001, 2008). However, a recently developed technique, based on the observation of the wake formed behind the charged spacecraft by the supersonic flow of the low-energy ions, allows the detection of these populations (Engwall et al., 2006, 2009). An analysis by André and Cully (2012) of the Cluster dayside data, using this technique, showed that the lowenergy ions can dominate $50-70 \%$ of the time the region inside of the magnetopause, even at sectors where no plasmaspheric plumes are observed. This provides additional evidence for the plasmaspheric wind.

These low-energy ions, in the outer magnetosphere, can also be detected by measuring the difference between the total plasma density, provided by the plasma frequency, and the hot ion density measured by a particle detector as the CISHIA instrument (Sauvaud et al., 2001). Following long periods of very weak activity, low-energy $\mathrm{H}^{+}, \mathrm{He}^{+}$and $\mathrm{O}^{+}$ions can be detected in a region adjacent to the magnetopause and on its magnetospheric side. Recurrent motions of the magnetopause accelerate these ions, which can then gain adequate energy to overcome the spacecraft potential barrier and become intermittently detectable by the ion instrument.

The low-energy ion observations reported by Sauvaud et al. (2001) were performed during the first year of the Clus- ter spacecraft operation, during which the high-inclination orbit allowed surveyance of the high-latitude magnetopause. With the spacecraft orbit evolution, however, it is now possible to examine the lower latitudes. Such an observation by the CIS-HIA instrument, in the outer dayside magnetosphere at equatorial latitudes $\left(Z_{\mathrm{GSM}}=1.5 R_{\mathrm{E}}\right.$ for $R=$ $10 R_{\mathrm{E}}, \mathrm{MLT}=13.6$ ), is shown in the example of Fig. 10 . Following a prolonged period of very quiet magnetospheric conditions (several days of Kp between 0 and 1), the HIA sensor intermittently detected this "hidden" dense population of cold ions as a series of bursts at around 20:02, 20:18, and 20:38 UT on 8 January 2013. The measured ion density reached then values up to $\sim 20 \mathrm{~cm}^{-3}$, against an ambient density of $0.5 \mathrm{~cm}^{-3}$ in the dayside plasma sheet.

All these observations provide a consistent picture for the existence of a plasmaspheric wind, steadily transporting cold plasma outwards, across the geomagnetic field lines. This wind can provide a substantial contribution to the magnetospheric plasma populations. Similar winds should also exist around other planets, or astrophysical objects, that are quickly rotating and have an ionised atmosphere as well as an intrinsic magnetic field, and would constitute an additional mode for atmospheric escape into space. 
Acknowledgements. The author is grateful to Joseph F. Lemaire for stimulating discussions of the plasmaspheric wind. He is also grateful to Henri Rème, George K. Parks and Nicolas André for helpful discussions and comments.

The CIS experiment was prepared by an international team. The CIS-CODIF instrument was calibrated by Lynn M. Kistler, University of New Hampshire. The RPA device was calibrated by Michael McCarthy, University of Washington. The CIS-HIA instrument was calibrated at IRAP and then in-flight at the Institute for Space Sciences at Bucharest by Adrian Blagau. The CIS telemetry data were processed and archived by Alain Barthe, and the $c l$ data analysis software tool was developed by Emmanuel Penou, both at IRAP. French participation in the Cluster project is funded by CNES; US participation is funded by NASA.

The EFW data are provided by the EFW experiment team and the CAA (Cluster Active Archive), ESA. The Kp index is provided by the GeoForschungsZentrum (GFZ) Potsdam.

Topical Editor I. A. Daglis thanks A. Masson and one anonymous referee for their help in evaluating this paper.

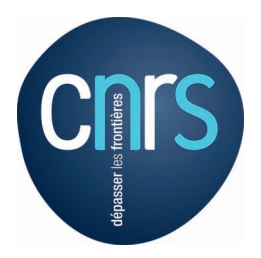

The publication of this article is financed by CNRS-INSU.

\section{References}

André, M. and Cully, C. M.: Low-energy ions: A previously hidden solar system particle population, Geophys. Res. Lett., 39, L03101, doi:10.1029/2011GL050242, 2012.

André, N. and Lemaire, J. F.: Convective instabilities in the plasmasphere, J. Atmos. Sol.-Terr. Phys., 68, 213-227, 2006.

Borovsky, J. E. and Denton, M. H.: A statistical look at plasmaspheric drainage plumes, J. Geophys. Res., 113, A09221, doi:10.1029/2007JA012994, 2008.

Dandouras, I., Pierrard, V., Goldstein, J., Vallat, C., Parks, G. K., Rème, H., Gouillart, C., Sevestre, F., McCarthy, M., Kistler, L. M., Klecker, B., Korth, A., Bavassano-Cattaneo, M. B., Escoubet, P., and Masson, A.: Multipoint observations of ionic structures in the Plasmasphere by CLUSTER-CIS and comparisons with IMAGE-EUV observations and with Model Simulations, AGU Monograph: Inner Magnetosphere Interactions: New Perspectives from Imaging, 159, 23—53, doi:10.1029/159GM03, 2005.

Dandouras, I., Cao, J., and Vallat, C.: Energetic ion dynamics of the inner magnetosphere revealed in coordinated ClusterDouble Star observations, J. Geophys. Res., 114, A01S90, doi:10.1029/2007JA012757, 2009.

Darrouzet, F., Gallagher, D. L., André, N. , Carpenter, D. L., Dandouras, I., Décréau, P. M. E., De Keyser, J., Denton, R. E., Foster, J. C., Goldstein, J., Moldwin, M. B., Reinisch, B. W., Sandel, B. R., and Tu, J.: Plasmaspheric density structures and dynamics: properties obsereved by the Cluster and Image missions, Space Sci. Rev., 145, 55-106, doi:10.1007/s11214-008-9438-9, 2009.

Décréau, P. M. E., Fergeau, P., Krasnoselskikh, V., Le Guirriec, E., Lévêque, M., Martin, Ph., Randriamboarison, O., Rauch,
J. L., Sené, F. X., Séran, H. C., Trotignon, J. G., Canu, P., Cornilleau, N., de Féraudy, H., Alleyne, H., Yearby, K., Mögensen, P. B., Gustafsson, G., André, M., Gurnett, D. C., Darrouzet, F., Lemaire, J., Harvey, C. C., Travnicek, P., and Whisper experimenters: Early results from the Whisper instrument on Cluster: an overview, Ann. Geophys., 19, 1241-1258, doi:10.5194/angeo-19-1241-2001, 2001.

Engwall, E., Eriksson, A. I., André, M., Dandouras, I., Paschmann, G., Quinn, J., and Torkar, K.: Low-energy (order $10 \mathrm{eV}$ ) ion flow in the magnetotail lobes inferred from spacecraft wake observations, Geophys. Res. Lett., 33, L06110, doi:10.1029/2005GL025179, 2006.

Engwall, E., Eriksson, A. I., Cully, C. M., André, M., Torbert, R., and Vaith, H.: Earth's ionospheric outflow dominated by hidden cold plasma, Nature Geosci., 2, 24-27, doi:10.1038/ngeo387, 2009.

Escoubet, C. P., Fehringer, M., and Goldstein, M.: Introduction: The Cluster mission, Ann. Geophys., 19, 1197-1200, doi:10.5194/angeo-19-1197-2001, 2001.

Goldstein, J., Sandel, B. R., Hairston, M. R., and Reiff, P. H.: Control of plasmaspheric dynamics by both convection and sub-auroral polarization stream, Geophys. Res. Lett., 30, 2243, doi:10.1029/2003GL018390, 2003.

Gustafsson, G., André, M., Carozzi, T., Eriksson, A. I., Fälthammar, C.-G., Grard, R., Holmgren, G., Holtet, J. A., Ivchenko, N., Karlsson, T., Khotyaintsev, Y., Klimov, S., Laakso, H., Lindqvist, P.-A., Lybekk, B., Marklund, G., Mozer, F., Mursula, K., Pedersen, A., Popielawska, B., Savin, S., Stasiewicz, K., Tanskanen, P., Vaivads, A., and Wahlund, J.-E.: First results of electric field and density observations by Cluster EFW based on initial months of operation, Ann. Geophys., 19, 1219-1240, doi:10.5194/angeo19-1219-2001, 2001.

Haaland, S., Lybekk, B., Svenes, K., Pedersen, A., Förster, M., Vaith, H., and Torbert, R.: Plasma transport in the magnetotail lobes, Ann. Geophys., 27, 3577-3590, doi:10.5194/angeo-273577-2009, 2009.

Kotova, G. A.: The Earth's Plasmasphere: State of Studies (a Review), Geomagn. Aeronomy, 47, 409-422, 2007.

Lemaire, J. F.: The formation of the light-ion trough and peeling off the plasmasphere, J. Atmos. Sol.-Terr. Phys., 63, 1285-1291, 2001.

Lemaire, J. F. and Gringauz, K. I.: The Earth's Plasmasphere, Cambridge University Press, Cambridge, 1998.

Lemaire, J. F. and Schunk, R. W.: Plasmaspheric wind, J. Atmos. Terr. Phys., 54, 467-477, 1992.

Li, K., Haaland, S., Eriksson, A., André, M., Engwall, E., Wei, Y., Kronberg, E. A., Fränz, M., Daly, P. W., Zhao, H., and Ren, Q. Y.: On the ionospheric source region of cold ion outflow, Geophys. Res. Lett., 39, L18102, doi:10.1029/2012GL053297, 2012.

McIlwain, C. E.: A Kp dependent equatorial electric field model, Adv. Space Res., 6, 187-197, 1986.

Meyer-Vernet, N.: Basics of the Solar Wind, Cambridge University Press, New York, 2007.

Moore, T. E., Fok, M.-C., Chandler, M. O., Chappell, C. R., Christon, S. P., Delcourt, D. C., Fedder, J., Huddleston, M., Liemohn, M., Peterson, W. K., and Slinker, S.: Plasma sheet and (nonstorm) ring current formation from solar and polar wind sources, J. Geophys. Res., 110, A02210, doi:10.1029/2004JA010563, 2005. 
Obana, Y., Menk, F. W., and Yoshikawa, I.: Plasma refilling rates for $L=2.3-3.8$ flux tubes, J. Geophys. Res., 115, A03204, doi:10.1029/2009JA014191, 2010.

Park, C. G.: Whistler observations of the interchange of ionization between the ionosphere and the protonosphere, J. Geophys. Res., 75, 4249, doi:10.1029/JA075i022p04249, 1970.

Pedersen, A., Décréau, P., Escoubet, C.-P., Gustafsson, G., Laakso, H., Lindqvist, P.-A., Lybekk, B., Masson, A., Mozer, F., and Vaivads, A.: Four-point high time resolution information on electron densities by the electric field experiments (EFW) on Cluster, Ann. Geophys., 19, 1483-1489, doi:10.5194/angeo-19-14832001, 2001.

Pedersen, A., Lybekk, B., André, M., Eriksson, A., Masson, A., Mozer, F. S., Lindqvist, P.-A., Décréau, P. M. E., Dandouras, I., Sauvaud, J.-A., Fazakerley, A., Taylor, M., Paschmann, G., Svenes, K. R., Torkar, K., and Whipple, E.: Electron density estimations derived from spacecraft potential measurements on Cluster in tenuous plasma regions, J. Geophys. Res., 113, A07S33, doi:10.1029/2007JA012636, 2008.

Pierrard, V., Khazanov, G. V., Cabrera, J., and Lemaire, J.: Influence of the convection electric field models on predicted plasmapause positions during magnetic storms, J. Geophys. Res., 113, A08212, doi:10.1029/2007JA012612, 2008.

Pierrard, V., Goldstein, G., André, N., Jordanova, V. K., Kotova, G. A., Lemaire, J. F., Liemohn, M. W., and Matsui, H.: Recent progress in physics-based models of the plasmasphere, Space Sci. Rev., 145, 193-229, doi:10.1007/s11214-008-9480-7, 2009.

Rème, H., Aoustin, C., Bosqued, J. M., Dandouras, I., Lavraud, B., Sauvaud, J. A., Barthe, A., Bouyssou, J., Camus, Th., Coeur-Joly, O., Cros, A., Cuvilo, J., Ducay, F., Garbarowitz, Y., Medale, J. L., Penou, E., Perrier, H., Romefort, D., Rouzaud, J., Vallat, C., Alcaydé, D., Jacquey, C., Mazelle, C., d'Uston, C., Möbius, E., Kistler, L. M., Crocker, K., Granoff, M., Mouikis, C., Popecki, M., Vosbury, M., Klecker, B., Hovestadt, D., Kucharek, H., Kuenneth, E., Paschmann, G., Scholer, M., Sckopke, N., Seidenschwang, E., Carlson, C. W., Curtis, D. W., Ingraham, C., Lin, R. P., McFadden, J. P., Parks, G. K., Phan, T., Formisano, V., Amata, E., Bavassano-Cattaneo, M. B., Baldetti, P., Bruno, R., Chionchio, G., Di Lellis, A., Marcucci, M. F., Pallocchia, G., Korth, A., Daly, P. W., Graeve, B., Rosenbauer, H., Vasyliunas, V., McCarthy, M., Wilber, M., Eliasson, L., Lundin, R., Olsen, S., Shelley, E. G., Fuselier, S., Ghielmetti, A. G., Lennartsson, W., Escoubet, C. P., Balsiger, H., Friedel, R., Cao, J.-B., Kovrazhkin, R. A., Papamastorakis, I., Pellat, R., Scudder, J., and Sonnerup, B.: First multispacecraft ion measurements in and near the Earth's magnetosphere with the identical Cluster ion spectrometry (CIS) experiment, Ann. Geophys., 19, 1303-1354, doi:10.5194/angeo19-1303-2001, 2001.
Sandel, B. R., Goldstein, J., Gallagher, D. L., and Spasojević, M.: Extreme ultraviolet imager observations of the structure and dynamics of the plasmasphere, Space Sci. Rev., 109, 25-46, 2003.

Sauvaud, J.-A., Lundin, R., Rème, H., McFadden, J. P., Carlson, C., Parks, G. K., Möbius, E., Kistler, L. M., Klecker, B., Amata, E., DiLellis, A. M., Formisano, V., Bosqued, J. M., Dandouras, I., Décréau, P., Dunlop, M., Eliasson, L., Korth, A., Lavraud, B., and McCarthy, M.: Intermittent thermal plasma acceleration linked to sporadic motions of the magnetopause, first Cluster results, Ann. Geophys., 19, 1523-1532, doi:10.5194/angeo-191523-2001, 2001.

Tsyganenko, N. A.: A magnetospheric magnetic field model with a warped tail current sheet, Planet. Space Sci., 37, 5-20, 1989.

Tu, J., Song, P., Reinisch, B. W., and Green, J. L. : Smooth electron density transition from plasmasphere to the subauroral region, J. Geophys. Res., 112, A05227, doi:10.1029/2007JA012298, 2007.

Vallat, C., Ganushkina, N., Dandouras, I., Escoubet, C. P., Taylor, M. G. G. T., Laakso, H., Masson, A., Sauvaud, J.-A., Rème, H., and Daly, P.: Ion multi-nose structures observed by Cluster in the inner Magnetosphere, Ann. Geophys., 25, 171-190, doi:10.5194/angeo-25-171-2007, 2007.

Volland, H.: A semiempirical model of large-scale magnetospheric electric fields, J. Geophys. Res., 78, 171-179, 1973.

Yoshikawa, I., Yamazaki, A., Yamashita, K., Takizawa, Y., and Nakamura, M.: Which is a significant contributor for outside of the plasmapause, an ionospheric filling or a leakage of plasmaspheric materials?: Comparison of He II ( $304 \AA$ ) images, J. Geophys. Res., 108, 1080, doi:10.1029/2002JA009578, 2003. 